\title{
Suplementação Energética na Recria de Fêmeas de Corte em Pastagem Cultivada de Inverno. Dinâmica da Pastagem
}

\section{Fabiana Kellermann de Freitas ${ }^{1}$, Marta Gomes da Rocha ${ }^{2}$, Ivan Luiz Brondani ${ }^{3}$, João Restle ${ }^{4}$, Fabio Pereira Neves ${ }^{5}$, Dalton Roso ${ }^{5}$, Vagner Guasso da Costa ${ }^{6}$}

RESUMO - Foi avaliada a dinâmica da pastagem de aveia preta (Avena strigosa Schreb) mais azevém (Lolium multiflorum Lam) utilizada por novilhas de corte submetidas a diferentes níveis de suplemento durante o período de pastejo. Os tratamentos foram: 'Sem Suplemento'- animais em pastagem de aveia mais azevém; 'Crescente' - animais em pastagem de aveia mais azevém, recebendo níveis crescentes de suplemento $(0,3 ; 0,6 ; 0,9 ; 1,2$ a 1,5\% do peso vivo [PV]) durante o ciclo da pastagem; 'Fixo' - animais em pastagem de aveia mais azevém, recebendo $0,9 \%$ do PV de suplemento durante todo o ciclo da pastagem; e 'Decrescente' - animais em pastagem de aveia mais azevém, recebendo níveis decrescentes de suplemento $(1,5 ; 1,2 ; 0,9 ; 0,6$ a $0,3 \%$ do PV) durante o ciclo da pastagem. O suplemento utilizado foi farelo de trigo. Foram avaliadas a massa de forragem, taxa de acúmulo diário de MS, oferta de forragem, oferta de lâminas foliares verdes, massa de forragem verde e relação folha:colmo. Na composição botânica da pastagem foram avaliados os percentuais dos componentes folha de aveia, colmo de aveia, folha de azevém, colmo de azevém e material morto na MF. O valor nutritivo da forragem aparentemente consumida pelos animais foi avaliado com base nos teores de proteína bruta e na digestibilidade in vitro da matéria orgânica, nutrientes digestíveis totais e fibra em detergente neutro. As variáveis estudadas não foram afetadas pela suplementação ou pela variação no nível de suplemento. O ciclo da pastagem interferiu nas variáveis estudadas.

Palavras-chave: Avena strigosa, farelo de trigo, Lolium multiflorum, oferta de lâminas foliares verdes, pastejo contínuo

\section{Energetic Supplementation on Rearing of Beef Heifers in Winter Cultivated Pasture. Pasture Dynamic}

\begin{abstract}
The objective of this trial was to study the dynamics of pasture containing black oat (Avena strigosa Schreb) plus ryegrass (Lolium multiflorum Lam) on beef heifers receiving different levels of supplementation. The following treatments were used: 'No Supplement' - animals in black oat plus ryegrass pasture; 'Increasing' - animals in black oat plus ryegrass pasture and fed increasing levels of supplement: $0.3 ; 0.6 ; 0.9$; and 1.2 to $1.5 \%$ of body weight (BW) during the pasture cycle; 'Fixed' - animals in black oat plus ryegrass pasture and fed $0.9 \%$ of BW as supplement during the entire pasture cycle; or 'Decreasing' - animals in black oat plus ryegrass pasture and fed decreasing levels of supplement: $1.5 ; 1.2 ; 0.9$; and 0.6 to $0.3 \%$ of BW during the pasture cycle. The supplement contained only wheat bran. The following variables were measured: forage yield, rate of daily accumulation of DM, forage allowance, green leaf allowance, green forage mass, and leaf:stem ratio. Oat leaf, oat stem, ryegrass leaf, ryegrass stem, and dead material all expressed as a percentage of FM were also evaluated. The nutritive value of the forage apparent consumed by the heifers was determined through measurements of contents of crude protein (CP), 'in vitro' organic matter digestibility, total digestible nutrients, and neutral detergent fiber. Although pasture cycle did affect the studied variables, the opposite was observed with different levels of supplementation in the current trial.
\end{abstract}

Key Words: Avena strigosa, wheat bran, Lolium multiflorum, green leaf allowance, continuous grazing

\section{Introdução}

Animais com altas exigências, como novilhas em recria para acasalamento com um ano de idade, necessitam de oferta de forragem constante, pois mudanças estacionais no padrão de crescimento das pastagens podem afetar negativamente o seu desem- penho. A correta planificação da produção animal, o manejo dos sistemas forrageiros, a confecção e utilização de reservas de qualidade e a suplementação são as principais ferramentas disponíveis para compatibilizar a oferta com a demanda de nutrientes nas diferentes categorias produtivas (Kloster \& Amigone, 1999).

\footnotetext{
${ }^{1}$ Eng. Agr. Aluna do Programa de Pós-Graduação em Zootecnia, Universidade Federal de Santa Maria (fkfreitas@hotmail.com).

2 Eng. Agr. Dra., Profa. Adjunto do Depto. de Zootecnia, UFSM. E.mail: tata@pro.via-rs.com.br; Rua Tuiuti, 1554 ap 201 cep $97105-662$ Santa Maria, RS

3 Zoot. Dr., Prof. Adjunto do Depto. de Zootecnia, UFSM. E.mail: brondani@ccr.ufsm.br

${ }^{4}$ Eng. Agr. PhD, Prof. Titular do Depto. de Zootecnia, UFSM. E.mail: jorestle@ccr.ufsm.br

${ }^{5}$ Aluno do Curso de Graduação em Agronomia, UFSM. bolsista FAPERGS. E.mail: setorforrageiras@bol.com.br

${ }^{6}$ Aluno do Curso de Graduação em Zootecnia, UFSM. E.mail: setorforrageiras@bol.com.br
} 
O planejamento de uma atividade pecuária baseada em pastagens implica em conhecer o padrão de distribuição da produção de forragem ao longo da estação de crescimento, estimar a produtividade de forragem esperada e definir a carga animal em função dos ganhos individuais de peso projetados para cada categoria.

As misturas de espécies forrageiras anuais de inverno visam combinar os picos de produção de matéria seca atingidos em diferentes épocas, de acordo com a espécie, resultando em aumento da produção e do período de utilização da pastagem (Roso et al., 1999). As aveias tendem a concentrar grande parte de sua produção no primeiro crescimento (no outono), que pode representar praticamente toda a forragem obtida com esta espécie durante o ciclo. Para equilibrada oferta de forragem, pode ser utilizada sua mistura com azevém, que apresenta produção em época mais tardia.

A suplementação de animais em pastejo é feita com o objetivo principal de manter o desempenho animal quando a massa ou a qualidade da forragem torna-se limitante (Prache et al., 1990). A incorporação de concentrados energéticos tem se mostrado muito eficaz para compensar o desempenho animal no período inicial de utilização dos cereais de inverno (Kloster \& Amigone, 1999). Com o decréscimo da qualidade da forragem no final do ciclo das gramíneas, a suplementação torna-se uma alternativa para atender às exigências dos animais.

Características da pastagem têm sido estudadas principalmente por sua influência sobre o consumo de forragem e o comportamento ingestivo. Portanto, o conhecimento de atributos que caracterizam a condição da pastagem, quando associado com informações quantitativas da forragem disponível, é de grande interesse para a tomada de decisões quanto ao manejo do pastejo (Canto et al., 2001).

No manejo da pastagem, deve-se, ao mesmo tempo, manter área foliar fotossinteticamente ativa e permitir que animais colham grandes quantidades de tecido foliar de alta qualidade (Pedreira et al., 2001), para se maximizar a produção forrageira, a eficiência de conversão da forragem produzida, a estabilidade da pastagem, o desempenho animal e a produção animal por hectare (Gomide \& Gomide, 2001). Massa de forragem verde, massa e oferta de forragem, oferta de lâminas foliares verdes, relação folha/colmo e componentes da pastagem merecem quantificação em experimentos que utilizam suplementação aos animais em pastejo, para que seja melhor compreendida a relação pastagem-animal-suplemento.

O objetivo neste trabalho foi avaliar a composição química e a dinâmica de uma pastagem de aveia preta mais azevém pastejada por novilhas de corte submetidas à variações no nível de suplementação energética.

\section{Material e Métodos}

O experimento foi desenvolvido em área do Departamento de Zootecnia da Universidade Federal de Santa Maria, localizado na região fisiográfica denominada Depressão Central, com altitude de 95 m, latitude $29^{\circ} 43^{\prime}$ Sul e longitude $53^{\circ} 42^{\prime}$ Oeste. A área experimental pertence à unidade de mapeamento São Pedro e apresenta solo classificado como Argissolo Vermelho Distrófico arênico (EMBRAPA, 1999). O clima da região é Cfa (subtropical úmido), conforme classificação de Köppen (Moreno, 1961). A análise de solo da área experimental revelou os seguintes valores médios: $\mathrm{pH}-\mathrm{H}_{2} \mathrm{O}$ : 5,2; índice SMP: 5,6; $\%$ argila: $26 \mathrm{~m} / \mathrm{V}$; P: 12,0 mg/L; K: 94,2 mg/L; \% MO: $3,2 \mathrm{~m} / \mathrm{V} ; \mathrm{Al}: 0,4 \mathrm{cmol}_{\mathrm{c}} / \mathrm{L} ; \mathrm{Ca}: 7,0 \mathrm{cmol}_{\mathrm{c}} / \mathrm{L} ; \mathrm{Mg}$ : $3,6 \mathrm{cmol}_{\mathrm{c}} / \mathrm{L}$; saturação de bases: $70 \%$ e saturação de Al: 3\%. Os dados médios mensais de temperatura e precipitação, durante o período experimental, foram obtidos na Estação Meteorológica da UFSM.

A área experimental foi dividida em 12 potreiros de aproximadamente um hectare cada, totalizando 11,7 ha, mais uma área contígua de 4,6 ha, destinada à permanência dos animais reguladores.

A pastagem foi implantada pelo sistema de plantio direto nos dias 8 e 9 de maio de 2003, utilizando-se uma mistura de aveia (Avena strigosa Schreb.) mais azevém (Lolium multiflorum Lam.). A densidade utilizada foi de $100 \mathrm{~kg} /$ ha de semente de aveia e $50 \mathrm{~kg} /$ ha de semente de azevém. A semente de azevém foi distribuída em linha (60\%) e, posteriormente, a lanço (40\%). A adubação constou de $250 \mathrm{~kg} / \mathrm{ha}$ de adubo organo-mineral de fórmula 7-10-10 e, em cobertura, foram aplicados $127 \mathrm{~kg} /$ ha de N, na forma de uréia, em três aplicações, nos dias 24/06, 02/08 e 28/08/2003.

Para avaliar a dinâmica da pastagem, novilhas de corte foram submetidas aos seguintes tratamentos: 'Sem Suplemento'- animais exclusivamente em pastagem de aveia mais azevém; 'Crescente' - animais em pastagem de aveia mais azevém, recebendo níveis crescentes de suplemento $(0,3 ; 0,6 ; 0,9 ; 1,2$ a $1,5 \%$ do peso vivo [PV]) durante o ciclo da pastagem; 'Fixo' 
- animais em pastagem de aveia mais azevém, recebendo $0,9 \%$ do PV de suplemento durante todo o ciclo da pastagem; e 'Decrescente' - animais em pastagem de aveia mais azevém, recebendo níveis decrescentes de suplemento $(1,5 ; 1,2 ; 0,9 ; 0,6$ a $0,3 \%$ do PV) durante o ciclo da pastagem. O suplemento utilizado foi farelo de trigo, fornecido diariamente às $14 \mathrm{~h}$, em quantidade ajustada de acordo com a carga animal mantida nos potreiros, por meio da estimativa de ganho dos animais.

O período de estabelecimento da pastagem foi de 56 dias e o de pastejo, de 112 dias (13 de julho a 01 de novembro). Foi realizado um período de adaptação de sete dias e os demais períodos, excetuando-se o último (28 dias), foram de 21 dias.

Utilizou-se o método de pastejo contínuo com lotação variável, utilizando-se três novilhas-teste e um número variável de reguladoras por repetição. As novilhas-teste permaneceram nos potreiros durante todo o período de utilização da pastagem, enquanto as reguladoras foram utilizadas para adequar a carga animal dos potreiros pela técnica 'put-and-take' (Mott \& Lucas, 1952), procurando-se manter a mesma massa de forragem em todos os tratamentos. As massas de forragem pretendidas variaram de $1.000 \mathrm{~kg} / \mathrm{ha}$ de MS, no início do período de pastejo, $1.200-1.300 \mathrm{~kg} / \mathrm{ha}$ de MS, na fase intermediária do ciclo das forrageiras, até $1.500 \mathrm{~kg} / \mathrm{ha}$ de MS no final do período de utilização da pastagem.

Foram utilizadas 80 novilhas cruzas CharolêsNelore. As novilhas-teste eram dos grupos genéticos 11/16 Charolês/Nelore, 5/8 Charolês/Nelore e 5/8 Nelore/Charolês e pertenciam ao rebanho do Setor de Bovinocultura de Corte do Departamento de Zootecnia da UFSM, apresentando idade inicial de oito meses e peso médio de 149,3 kg, em julho de 2003.

As pesagens dos animais foram realizadas em intervalos de 21 dias, exceto no último período de avaliação, que foi de 28 dias, respeitado-se um jejum prévio de 12 horas.

Para determinação da massa de forragem, expressa em $\mathrm{kg} / \mathrm{ha}$ de MS, foi utilizada a técnica de dupla amostragem (Wilm et al., 1944). Em cada potreiro, foram feitas vinte estimativas visuais e cinco cortes, realizados com uma tesoura de esquila em um quadrado com área de $0,25 \mathrm{~m}^{2}$. A forragem foi pesada e o valor obtido foi extrapolado para $\mathrm{kg} / \mathrm{ha}$ de MS. Esta avaliação foi realizada em intervalos de dez dias. A forragem proveniente das coletas foi homogeneizada e dividida em duas subamostras, uma para determinação do teor de MS da pastagem e outra para separação botânica.

Para determinação da composição botânica, foram separados manualmente os componentes da subamostra (folha, colmo e material morto), pesados e secos a $60^{\circ} \mathrm{C}$ em estufa de circulação forçada, até peso constante. Foi calculada a participação dos seguintes componentes na massa de forragem (MF): lâmina de aveia, colmo de aveia, lâmina de azevém, colmo de azevém e material morto. Com a MF, a carga animal $(\mathrm{kg} / \mathrm{ha}$ de PV) utilizada em cada período de avaliação e a porcentagem de lâmina foliar presente na pastagem nos períodos de avaliação, calculou-se a oferta de folhas, em kg MS/100 kg PV.

Para a avaliação da taxa de acúmulo de MS (TAD), foram utilizadas três gaiolas de exclusão ao pastejo por potreiro (repetição), segundo metodologia descrita por Klingman et al. (1943). No início e final do pastejo, em cada período experimental, um ponto representativo da área a ser avaliada foi escolhido para a locação de cada gaiola $(G)$. Outro ponto com disponibilidade de forragem semelhante, denominado 'fora de gaiola' (FG) foi selecionado para o corte, feito com tesoura de esquila, em um quadrado de $0,25 \mathrm{~m}^{2}$ de área, para determinação da quantidade de forragem presente no momento da locação da gaiola. As amostras de cada G e FG foram levadas à estufa, secas e pesadas. A TAD foi obtida pela diferença no peso da amostra seca dos cortes $G$ da avaliação i e FG da avaliação i-1 dividido pelo número de dias do período. A TAD por tratamento por período foi obtida pela média dos valores calculados em cada repetição do mesmo tratamento.

O valor nutritivo da forragem aparentemente consumida pelos animais foi determinado a partir de análise laboratorial de amostras colhidas por meio de simulação de pastejo (Euclides et al., 1992). As amostras colhidas foram pesadas e secas em estufa de ventilação forçada a $65^{\circ} \mathrm{C}$ por 72 horas, pesadas novamente e processadas em moinho tipo Willey, para posteriores análises. Avaliou-se o teor de proteína bruta $(\mathrm{PB})$ e a digestibilidade in vitro da matéria orgânica (DIVMO) e fibra em detergente neutro (FDN), de acordo com técnicas descritas pela AOAC (1984), por Tilley \& Terry (1963) e Goering \& Van Soest (1970), respectivamente. O teor de nutrientes digestíveis totais (NDT) foi calculado pelo produto entre a porcentagem de matéria orgânica $(\% \mathrm{MO})$ e da digestibilidade in vitro da matéria orgânica (\%DIVMO), dividido por 100. 
O delineamento experimental foi inteiramente casualizado, com quatro tratamentos e três repetições. Os resultados foram submetidos à análise de variância e, quando detectada diferença, as médias foram comparadas pelo teste Tukey a $5 \%$ de significância. Nas variáveis que apresentaram diferença entre períodos, realizou-se a análise de regressão, utilizando-se o pacote estatístico SAS versão 6.08 (1996). O modelo matemático geral referente à análise das variáveis estudadas foi representado por:

$$
\mathrm{Y}_{\mathrm{ijk}}=\mu+\mathrm{i}_{\mathrm{i}}+\mathrm{r}_{\mathrm{j}}\left(\mathrm{i}_{\mathrm{i}}\right)+\mathrm{a}_{\mathrm{k}}+(\mathrm{ia})_{\mathrm{ik}}+\sum_{\mathrm{ijk}}
$$

em que $Y_{i j k}$ representa as variáveis dependentes; $\mu$ é a média de todas as observações; $i_{i}$ corresponde ao efeito do i-ésimo tratamento; $r_{j}\left(i_{i}\right)$ é o efeito da j-ésima repetição dentro do i-ésimo tratamento (erro a); $\alpha_{k}, o$ efeito do k-ésimo período; (ia) ${ }_{\mathrm{ik}}$ representa a interação entre o i-ésimo tratamento e o k-ésimo período; e $\sum_{\mathrm{ijk}}$ corresponde ao erro experimental residual (erro b).

Para comparar os efeitos dos tratamentos e períodos de avaliação na composição botânica, foi utilizada estatística não-paramétrica com o uso de testes de aleatorização, por meio do programa MULTIV (Pillar, 1997).

\section{Resultados e Discussão}

Na Tabela 1 são apresentados os dados médios mensais de temperatura $\left({ }^{\circ} \mathrm{C}\right)$ e precipitação $(\mathrm{mm})$ no período de julho a novembro de 2003. Nos meses de julho a outubro, houve um déficit de $229,7 \mathrm{~mm}$ em relação à precipitação normal durante estes meses do ano. Mesmo com precipitação maior que a normal, no mês de novembro, o déficit não foi compensado.

Na Tabela 2 encontram-se os valores médios de massa de forragem (MF) e de massa de forragem verde (MFV) para os diferentes níveis de suplementação. Os animais foram submetidos a valores semelhantes $(\mathrm{P}>0,05)$ de $\mathrm{MF}$, o que provavelmente só foi possível em virtude do intervalo de dez dias entre as avaliações efetuadas e a observação visual diária para ajuste da carga animal. Houve diferença $(\mathrm{P}<0,05)$ entre períodos de avaliação para MF, conforme pretendido, com valores de $1.173,0 \mathrm{~kg} / \mathrm{ha}$ de MS no início do ciclo e aumento gradativo até $2.126,4 \mathrm{~kg} / \mathrm{ha}$ de MS no final do período de utilização da pastagem.

Em função da estrutura mais ereta da aveia e dos baixos teores de matéria seca da forragem, o início da utilização da pastagem ocorreu com baixos valores de MF. Este manejo, estimulando o perfilhamento, per-

\begin{tabular}{|c|c|c|c|c|}
\hline \multirow[t]{2}{*}{$\begin{array}{l}\text { Mês } \\
\text { Month }\end{array}$} & \multicolumn{2}{|c|}{$\begin{array}{c}\text { Temperatura média }\left({ }^{\circ} \mathrm{C}\right) \\
\text { Average temperature }\end{array}$} & \multicolumn{2}{|c|}{$\begin{array}{c}\text { Precipitação (mm) } \\
\text { Rainfall }\end{array}$} \\
\hline & $\begin{array}{l}\text { Normal } \\
\text { Expected }\end{array}$ & $\begin{array}{c}\text { Ocorrida } \\
\text { Actual }\end{array}$ & $\begin{array}{l}\text { Normal } \\
\text { Expected }\end{array}$ & $\begin{array}{l}\text { Ocorrida } \\
\text { Actual }\end{array}$ \\
\hline Julho (July) & 13,5 & 13,4 & 148,6 & 113,0 \\
\hline Agosto (August) & 14,6 & 13,5 & 137,4 & 73,9 \\
\hline Setembro (September) & 16,2 & 15,9 & 153,6 & 57,0 \\
\hline Outubro (October) & 18,8 & 20,0 & 145,6 & 111,6 \\
\hline Novembro (November) & 21,4 & 21,6 & 132,2 & 228,6 \\
\hline
\end{tabular}

Tabela 2 - Massa de forragem (MF, kg/ha de MS) e massa de forragem verde (MFV, kg/ha de MS) da pastagem de aveia (A. strigosa) mais azevém (L. multiflorum) utilizada por novilhas de corte

Table 2 - Forage yield (FY, kg/ha of DM) and green forage yields (GFM, kg/ha of DM) of oat (A. strigosa) plus ryegrass (L. multiflorum) pasture used by beef heifers

\begin{tabular}{lccccc}
\hline $\begin{array}{l}\text { Tratamento } \\
\text { Treatment }\end{array}$ & \multicolumn{3}{c}{$\begin{array}{c}\text { Período } \\
\text { Period }\end{array}$} & $\begin{array}{c}\text { Média } \\
\text { Mean }\end{array}$ \\
\cline { 2 - 5 } & $13 / 07-04 / 08$ & $05 / 08-23 / 08$ & $24 / 08-13 / 09$ & $14 / 09-04 / 10$ & $05 / 10-01 / 11$ \\
\hline MF $(F Y)$ & $1.173,0 \mathrm{~b}$ & $1.190,0 \mathrm{~b}$ & $1.336,7 \mathrm{~b}$ & $2.112,7 \mathrm{a}$ & $2.126,4 \mathrm{a}$ \\
MFV $(G F Y)$ & $1.079,4 \mathrm{~b}$ & $935,3 \mathrm{~b}$ & $1.074,6 \mathrm{~b}$ & $1.676,6 \mathrm{a}$ & $1.448,2 \mathrm{a}$ \\
\hline
\end{tabular}

a, b, c na mesma linha, diferem entre si $(P<0,05) ; a, b, c$ in the same row differ $(P<0.05)$. 
mitiu manter elevada relação lâmina foliar/colmo e evitar que houvesse, principalmente na aveia, elongação dos entrenós, elevando os meristemas apicais e facilitando sua eliminação pelo pastejo. $\mathrm{O}$ uso de MF variável durante o ciclo da pastagem foi também uma estratégia para manter MFV adequada, sem a presença prematura de material morto na pastagem. A MFV representou, em média, 83,5\% da MF nos primeiros 63 dias e 73,7\% entre 64 e 112 dias de utilização. A MF exerce importante efeito na composição botânica durante o período de pastejo, promovendo mudanças na estrutura da pastagem, determinando a participação dos componentes folha, colmo e material morto e alterando a qualidade da forragem disponível para os animais (Canto, 1994).

Durante o período de utilização da pastagem, a MF média foi $1.587,8 \mathrm{~kg} /$ ha de MS, dentro dos valores sugeridos por Mott (1984) de 1.200 a $1.600 \mathrm{~kg} / \mathrm{ha}$ de MS, para o máximo desempenho animal, em pastagens temperadas. A equação linear é a que melhor representa a variação da MF de acordo com o período de pastejo $\left(\mathrm{P}<0,05 ; \mathrm{R}^{2}=0,69\right)$, houve aumento de $13,04 \mathrm{~kg} / \mathrm{ha}$ de MS a cada dia de pastejo.

Em solo com nível médio de fósforo e suficiente de potássio, com déficit hídrico, em 112 dias de pastejo, a produção média de forragem foi $6.801,3 \mathrm{~kg} / \mathrm{ha}$ de MS. Em idêntico período de pastejo, na mesma área, Frizzo et al. (2003) observaram produção de $8.021 \mathrm{~kg} /$ ha de MS, com uso de $90 \mathrm{~kg} /$ ha de N. A utilização de $127 \mathrm{~kg} /$ ha de $\mathrm{N}$ correspondeu à quantidade (Soares \& Restle, 1999) indicada como mais economicamente rentável para esse sistema.

Na Figura 1 são apresentados os resultados de taxa de acúmulo diário de MS (TAD, $\mathrm{kg} \mathrm{MS/ha/dia).}$ As variações no nível de suplemento e na carga animal subseqüente não alteraram os valores de TAD, com diferença $(\mathrm{P}<0,05)$ entre os períodos de avaliação. A TAD apresentou comportamento linear, aumentando no decorrer do ciclo da pastagem.

Não foram observados na TAD reflexos de possíveis alterações no consumo de forragem decorrentes da suplementação que pudessem interferir na taxa de acúmulo de matéria seca da pastagem e na oferta de lâminas foliares (Gibb \& Treacher, 1976). Animais suplementados, ao consumirem preferencialmente plantas ou partes de plantas, especialmente folhas jovens, alteram a eficiência fotossintética da vegetação. Menor TAD foi observada em pastagem de aveia mais azevém quando os animais foram suplementados com

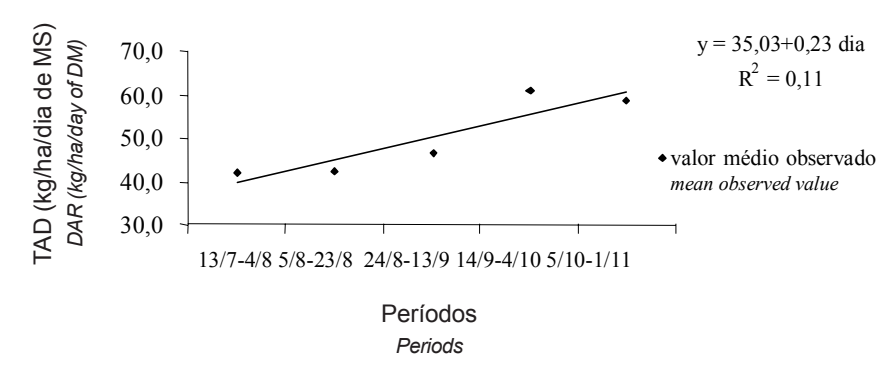

Figura 1 - Taxa de acúmulo diário de MS (TAD, kg de MS/ ha/dia) da pastagem de aveia ( $A$. strigosa) mais azevém (L. multiflorum) utilizada por novilhas de corte.

Figure 1 - Daily accumulation rate of DM (DAR, $\mathrm{kg}$ of DM/ha/ day) of oat (A. strigosa) plus ryegrass (L. multiflorum) pasture used by beef heifers.

resíduo de milho (Genro et al., 2001). Também Rocha et al. (2004) observaram comportamento semelhante (redução na TAD), em pastagem de aveia mais azevém 57 a 84 dias após o início do período de pastejo, com animais recebendo suplemento.

A TAD média mensurada neste trabalho $(50,6 \mathrm{~kg} /$ ha/dia de MS) está dentro da faixa de valores encontrados em pastagem de aveia + azevém, de $40 \mathrm{~kg} / \mathrm{ha} /$ dia de MS (Roso et al., 2003) a 56,5 kg/ha/dia de MS (Gonçalves et al., 2002). Entre as dificuldades enfrentadas no manejo de pastagens, está a grande variação no número de animais necessários para o ajuste da lotação, decorrente da oscilação na TAD, ocasionada pelas variações climáticas e pela estacionalidade de produção das espécies utilizadas (Roso et al., 1999).

De acordo com a equação de regressão, a cada dia do ciclo das forrageiras, a pastagem apresentou acúmulo de $0,23 \mathrm{~kg} /$ ha de MS. A lotação animal utilizada para manter a MF variável durante o ciclo das forrageiras permitiu que a intensidade e freqüência de desfolhação, determinando a quantidade de folhas colhidas pelo animal, não afetasse o crescimento da pastagem no período posterior, o que não ocorreu em anos anteriores, em trabalhos com as mesmas espécies forrageiras (Lupatini et al., 1998; Roso et al., 2000; Frizzo et al., 2003; Rocha et al., 2003; Pilau et al., 2005; Pilau et al., 2004b), em que a TAD apresentou comportamento quadrático durante o período de pastejo.

A partir dos dados da separação dos componentes da pastagem na massa de forragem, realizou-se uma análise de ordenação e, a partir desta, obteve-se o diagrama de ordenação (Figura 2), por meio do qual foi possível analisar a disposição dos componentes da pastagem, tratamentos e períodos no plano de ordena- 
ção e traçar as trajetórias dos tratamentos durante o ciclo da pastagem.

Grande parte da variação total dos componentes, (91,5\%) é explicada pelo diagrama de ordenação, em que $69,9 \%$ se justificam pelo eixo I e $21,6 \%$ pelo eixo II. No eixo I a correlação dos componentes folha de aveia, colmo de aveia, folha de azevém, colmo de azevém e material morto foi de - 0,$90 ;-0,90 ;-0,24 ; 0,95$ e 0,82 , respectivamente.

A correlação dos componentes folha de aveia, colmo de aveia, folha de azevém, colmo de azevém e material morto com o eixo II foi - $0,35,-0,30 ; 0,96 ;-0,17$ e $-0,07$. A descrição da composição botânica da pastagem é importante pelo fato de que os animais, quando submetidos à grande oferta de forragem, podem selecionar uma espécie em detrimento de outra (Grise et al., 2001).

De acordo com o diagrama de ordenação, a participação dos componentes folha e colmo de aveia na massa de forragem nos diferentes níveis de suplemento foi maior no período inicial de pastejo, comprovando a afirmação de Floss (1989) de que a aveia preta apresenta rápido crescimento inicial, com redução nos períodos posteriores. Esta observação foi realizada anteriormente por outros autores, que tam-

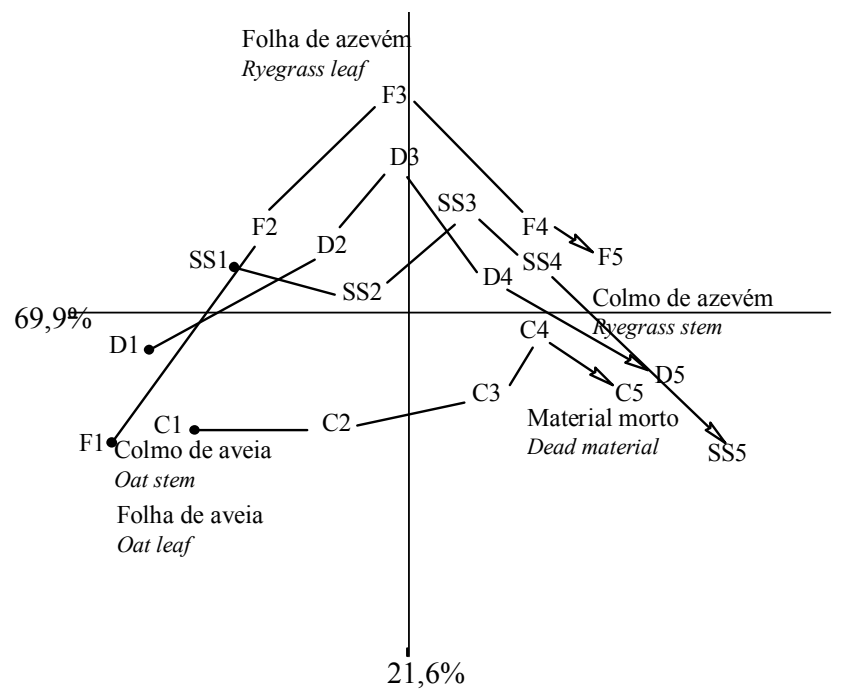

Figura 2 - Diagrama de ordenação dos componentes da pastagem de aveia ( $A$. strigosa) mais azevém (L. multiflorum) utilizada por novilhas de corte: SS = 'Sem Suplemento'; C = 'Crescente'; F = 'Fixo'; $D=$ 'Decrescente' $1=13 / 7-4 / 8 ; 2=5 / 8$ $23 / 8 ; 3=24 / 8-13 / 9 ; 4=14 / 9-4 / 10 ; 5=5 / 10-1 / 11$.

Figure 2 - Ordination diagram of components of oat (A. strigosa) plus ryegrass (L. multiflorum) pasture used by beef heifers: NS = 'No Supplement'; I= 'Increasing'; $F=$ 'Fixed'; $D=$ 'Decreasing' $1=13 / 7-4 / 8 ; 2=5 / 8-23 / 8$; $3=24 / 8-13 / 9 ; 4=14 / 9-4 / 10 ; 5=5 / 10-1 / 11$. bém avaliaram em pastagem de aveia + azevém (Frizzo et al., 2003; Roso \& Restle, 2000; Restle et al., 1998). No tratamento 'Crescente', a aveia demonstrou tendência de leve redução durante os períodos subseqüentes, contribuindo para o envelhecimento precoce da pastagem provocado pela presença de material morto já na fase intermediária do ciclo, em virtude da senescência de plantas, que, ao se aproximarem da fase reprodutiva, emitiram inflorescências e foram pastejadas, com eliminação dos pontos de crescimento. Também contribuiu para esta situação a pequena participação de folhas de azevém. Pequenas quantidades de suplemento $(0,3$ e $0,6 \% \mathrm{PV})$ devem ter interferido na seletividade animal, estimulando o maior consumo de lâminas foliares de azevém. De forma contrária, Frizzo et al. (2001) observaram que a preferência por lâminas foliares de azevém aumenta com o nível de suplementação. Nos demais níveis, no entanto, a participação de folha de azevém foi maior desde o início do período de pastejo, com comportamento crescente até final de agosto e meados de setembro. A composição botânica diferenciada não foi resultado do manejo inicial, que foi idêntico em todos os níveis de suplemento testados.

Quando a pastagem iniciou seu ciclo reprodutivo, a partir de setembro, a participação de colmo de azevém passou a ser importante na MF em todos os níveis de suplementação. A participação de inflorescências, tanto de aveia quanto de azevém, não foi significativa por ocasião da separação botânica, não sendo considerada na análise estatística. O acúmulo de material morto apresentou tendência similar nos tratamentos 'Sem Suplemento', 'Fixo' e 'Decrescente', com maior participação na MF a partir de 63 dias de utilização da pastagem.

Houve correlação altamente significativa, mas de baixo valor, entre o ganho médio diário e os componentes folha de azevém $(\mathrm{r}=0,45 ; \mathrm{P}<0,001)$ e material morto $(\mathrm{r}=-0,44 ; \mathrm{P}<0,001)$. Para os demais componentes, a correlação não foi significativa $(\mathrm{P}>0,05)$.

Os animais foram submetidos à mesma $(\mathrm{P}>0,05)$ oferta de forragem $(\mathrm{OF})$, que variou conforme o ciclo da pastagem $(\mathrm{P}<0,05$; Tabela 3$)$. A OF média foi de $7,4 \mathrm{~kg}$ de $\mathrm{MS} / 100 \mathrm{~kg} \mathrm{PV}$, mas o menor valor de OF ao final do ciclo da pastagem não deve ter interferido no desempenho individual, pois o máximo desempenho animal em espécies temperadas é alcançado na faixa de 4 a $6 \mathrm{~kg}$ MS/100 kg PV (Mott, 1984). A quantidade de forragem em oferta e sua composição 
estrutural exercem grande influência no desempenho dos animais em pastejo, principalmente em decorrência de sua influência sobre o consumo de forragem (Carvalho, 1997).

A OLFV (Tabela 3) foi a mesma para todos os níveis de suplementação $(\mathrm{P}>0,05)$, com redução no decorrer do período de pastejo $(\mathrm{P}<0,05)$, apesar do aumento na $\mathrm{MF}$, decorrente dos fatores de manejo, envelhecimento dos perfilhos e respostas fisiológicas das gramíneas às condições do meio ambiente (Canto et al., 2001). Há diminuição da participação do componente folhas verdes na composição da pastagem com o avançar do seu estágio de desenvolvimento (Figura 2). O valor médio de OLFV foi de 3,4 kg de MS/100 kg de PV, resultando em GMD de $0,957 \mathrm{~kg} /$ animal $/$ dia (Freitas et al., 2005). A oferta de folhas em pastagens é um parâmetro que explica adequadamente a resposta animal (Burns et al., 1989). Valores semelhantes de ganho, 0,812 kg/animal/dia, com 3,2 kg de MS de folhas/100 $\mathrm{kg}$ de PV, também foram observados em pastagem de aveia mais azevém (Genro et al., 2001).

A relação folha/colmo da pastagem não foi afetada $(\mathrm{P}>0,05)$ pela suplementação ou pela variação no nível de suplemento (Tabela 4), com exceção do final do período de pastejo, quando os animais do nível 'Fixo' provavelmente colheram menor quantidade de folhas $(\mathrm{P}<0,05)$, restando na pastagem maior quantidade de folhas em relação a de colmos.

Diferenças na relação folha/colmo nos períodos do ciclo das gramíneas $(\mathrm{P}<0,05)$ ocasionam, principalmente, diferenças na qualidade, densidade e no consumo de forragem. A diferença no padrão de crescimento entre as duas espécies formadoras da pastagem foi evidente nas proporções relativas de folha e colmo durante o período de pastejo. A relação folha/ colmo mostra-se mais baixa em duas situações, no início e final do ciclo da pastagem. No início, em razão da participação de colmos de aveia e, no final, pelo aumento na maturidade do azevém (Figura 2). Após três semanas de pastejo, e mantendo-se nas seis semanas seguintes, aumenta a relação folha/colmo, com os maiores valores na fase intermediária do ciclo.

Os valores percentuais de PB, DIVMO, NDT e FDN da forragem aparentemente consumida pelos animais encontram-se na Tabela 5. Não houve diferença $(P>0,05)$ entre níveis de suplemento para as médias de PB, DIVMO, NDT e FDN. Os animais colheram forragem de igual qualidade, independentemente da variação no nível de suplemento, provavelmente pelo fato de a MF e OF não terem sido limitantes. Houve, no entanto, variação dos teores com o decorrer do ciclo da pastagem $(\mathrm{P}<0,05)$.

O teor médio de PB foi de $24,1 \%$, superior ao de $15,1 \%$, referenciado pelo NRC (1984) para atender as exigências de novilhas de corte em recria com peso vivo de $200 \mathrm{~kg}$. Durante todo o período de utilização, as espécies estudadas apresentaram teor de proteína satisfatório para obtenção de elevado desempenho animal. A importância da utilização de um suplemento que atenda às exigências de $\mathrm{PB}$ dos animais é evidenciada no período equivalente ao final do ciclo da pastagem, quando a forragem aparentemente colhida pelos animais apresenta teor de PB abaixo do recomendado pelo NRC (1984). $\mathrm{O}$ menor nível de $\mathrm{PB}$, no entanto, é bastante superior à concentração de $1 \%$ de $\mathrm{N}$ na $\mathrm{MS}$, na qual a eficiência fermentativa das bactérias ruminais pode ser reduzida, diminuindo o consumo e a digestão. Concentrações limitantes de N não são usuais em pastagens temperadas (Hodgson, 1990). A maior proporção de lâminas de azevém (Figura 3) pode ter proporcionado seleção de dieta com maiores teores de $\mathrm{PB}(\mathrm{P}<0,05)$ pelos animais no período de 24/8 a 13/9 que nos demais períodos, de modo semelhante ao observado por Rocha et al. (2003).

A digestibilidade do material colhido permaneceu acima de $60 \%$ e o manejo empregado, variando a MF, não permitiu que a forragem residual de um período diminuísse a oportunidade de colheita de material com maior digestibilidade no período seguinte, com exce-

Tabela 3 - Oferta de forragem (OF) e de lâminas foliares verdes (OLFV) da pastagem de aveia ( $A$. strigosa) mais azevém (L. multiflorum) utilizada por novilhas de corte

Table 3 - Forage allowance (FA) and green leaf blade allowance (\%BW) of oat (A. strigosa) plus ryegrass (L. multiflorum) pasture used by beef heifers

\begin{tabular}{lcccccc}
\hline $\begin{array}{l}\text { Tratamento } \\
\text { Treatment }\end{array}$ & \multicolumn{5}{c}{$\begin{array}{c}\text { Período } \\
\text { Period }\end{array}$} & $\begin{array}{c}\text { Média } \\
\text { Mean }\end{array}$ \\
\cline { 2 - 5 } & $13 / 7-4 / 8$ & $5 / 8-23 / 8$ & $24 / 8-13 / 9$ & $14 / 9-4 / 10$ & $5 / 10-1 / 11$ & \\
\hline OF $(F A)$ & $8,7 \mathrm{a}$ & $6,6 \mathrm{ab}$ & $8,7 \mathrm{a}$ & $8,6 \mathrm{a}$ & $4,6 \mathrm{~b}$ & 7,4 \\
OLFV $($ GLA $)$ & $5,3 \mathrm{a}$ & $3,2 \mathrm{~b}$ & $4,1 \mathrm{ab}$ & $3,1 \mathrm{~b}$ & $1,1 \mathrm{c}$ & 3,4 \\
\hline
\end{tabular}

$a, b, c$ na mesma linha, diferem entre si $(P<0,05)(a, b, c$ in the same row differ $[P<0.05])$. 
Tabela 4 - Relação folha/colmo da pastagem de aveia ( $A$. strigosa) mais azevém ( $L$. multiflorum) utilizada por novilhas de corte

Table 4 - Leaf/stem ratio of oat (A. strigosa) plus ryegrass (L. multiflorum) pasture used by beef heifers

\begin{tabular}{|c|c|c|c|c|c|c|}
\hline \multirow[t]{2}{*}{$\begin{array}{l}\text { Tratamento } \\
\text { Treatment }\end{array}$} & \multicolumn{5}{|c|}{$\begin{array}{l}\text { Período } \\
\text { Period }\end{array}$} & \multirow[t]{2}{*}{$\begin{array}{l}\text { Média } \\
\text { Mean }\end{array}$} \\
\hline & $13 / 7-4 / 8$ & $5 / 8-23 / 8$ & $24 / 8-13 / 9$ & $14 / 9-4 / 10$ & $5 / 10-1 / 11$ & \\
\hline $\begin{array}{l}\text { Sem suplementação } \\
\text { No supplement }\end{array}$ & 0,20 & 1,50 & 1,73 & 0,87 & $0,33 \mathrm{~b}$ & 0,93 \\
\hline $\begin{array}{l}\text { Crescente } \\
\text { Increasing }\end{array}$ & 0,25 & 2,47 & 1,10 & 0,63 & $0,40 \mathrm{~b}$ & 0,97 \\
\hline $\begin{array}{l}\text { Fixo } \\
\text { Fixed }\end{array}$ & 0,35 & 2,30 & 2,07 & 0,97 & $0,93 \mathrm{a}$ & 1,32 \\
\hline $\begin{array}{l}\text { Decrescente } \\
\text { Decreasing }\end{array}$ & 0,50 & 2,03 & 1,50 & 0,77 & $0,47 \mathrm{~b}$ & 1,10 \\
\hline $\begin{array}{l}\text { Média } \\
\text { Mean }\end{array}$ & $0,32 \mathrm{c}$ & $2,08 \mathrm{a}$ & $1,60 \mathrm{ab}$ & $0,81 \mathrm{bc}$ & $0,53 \mathrm{c}$ & \\
\hline CV (\%) & 34,40 & 74,95 & 28,41 & 16,86 & 18,75 & \\
\hline
\end{tabular}

$a, b, c$ na mesma linha diferem entre si $(P<0,05)(a, b, c$ in the same row differ $[P<0.05])$.

Tabela 5 - Valores médios de conteúdo de proteína bruta $(\mathrm{PB})$, digestibilidade in vitro da matéria orgânica (DIVMO), nutrientes digestíveis totais (NDT) e fibra em detergente neutro (FDN) da forragem aparentemente consumida e do farelo de trigo

Table 5 - Mean values of crude protein (CP), in vitro organic matter digestibility (IVOMD), total digestible nutrients (TDN) and neutral detergent fiber (NDF) of forage and wheat bran apparently consumed

\begin{tabular}{lcccc}
\hline $\begin{array}{l}\text { Período } \\
\text { Period }\end{array}$ & PB & DIVMO & NDT & FDN \\
IVOMD & TDN & NDF \\
\hline 13/07-04/08 & $26,3 \mathrm{~b}$ & $60,0 \mathrm{~b}$ & $54,0 \mathrm{~b}$ & $31,4 \mathrm{~b}$ \\
05/08-23/08 & $26,6 \mathrm{~b}$ & $61,4 \mathrm{~b}$ & $56,0 \mathrm{~b}$ & $41,9 \mathrm{ab}$ \\
$24 / 8-13 / 09$ & $32,3 \mathrm{a}$ & $64,0 \mathrm{ab}$ & $58,2 \mathrm{ab}$ & $38,8 \mathrm{ab}$ \\
14/9-4/10 & $22,5 \mathrm{c}$ & $69,7 \mathrm{a}$ & $63,6 \mathrm{a}$ & $41,4 \mathrm{ab}$ \\
5/10-1/11 & $12,8 \mathrm{~d}$ & $61,4 \mathrm{~b}$ & $57,2 \mathrm{~b}$ & $54,4 \mathrm{a}$ \\
Média & 24,1 & 63,3 & 57,8 & 41,6 \\
Mean & & & & \\
Farelo de trigo & 22,2 & 70,4 & 65,5 & 42,0 \\
Wheat bran & & & &
\end{tabular}

a, b, c na mesma coluna diferem entre $\mathrm{si}(\mathrm{P}<0,05)(a, b, c$ in the same row differ $[P<0.05])$.

ção do período correspondente ao final do ciclo das forrageiras. Em pastagens com lotação contínua, quando eficientemente pastejada, os animais consomem folhas jovens e a digestibilidade da forragem consumida permanece alta. $\mathrm{O}$ efeito do aumento progressivo na parede celular que acompanha a maturidade das gramíneas não interferiu significativamente na DIVMO do material consumido, pois as novilhas colheram forragem de mesma digestibilidade tanto no início quanto no final do ciclo da pastagem e, com o aumento na MF, houve maior chance de seletividade. O valor médio de DIVMO (63,3\%) é intermediário aos valores médios encontrados em anos anteriores, na mesma área, em pastagem de gramíneas temperadas, de 54,0\% (Pilau et al., 2004) a 66,5\% (Soares \& Restle, 2002). Diferenças na DIVMO estão associadas a mudanças na estrutura da pastagem, como altura, conteúdo e distribuição de lâminas foliares, bainhas, colmo e material morto, tornando difícil a quantificação da importância de cada um destes fatores (Pilau et al., 2005). Estes autores afirmam que a maior disponibilidade de forragem per se não resulta necessariamente em dieta de melhor qualidade, pois novilhas em disponibilidade de forragem baixa e suplementadas com $0,7 \%$ do PV de grão de sorgo moído tiveram oportunidade de consumir forragem com maior DIVMO $(69 \%)$ e NDT (63\%) que as novihas em pastagem com alta disponibilidade de forragem e recebendo o mesmo nível de suplemento.

A variação do teor de NDT com o avanço do ciclo da pastagem $(\mathrm{P}<0,05)$ acompanhou a DIVMO, com maiores valores nos períodos com maior participação do componente folha de azevém (Figura 3 ). O valor médio de NDT da forragem aparentemente consumida pelas novilhas foi $57,8 \%$, semelhante ao encontrado por Rocha et al. (2003).

A fibra é considerada um índice negativo de qualidade (Euclides, 2000). O aumento no teor de FDN no final do ciclo é explicado pela composição botânica 
da pastagem, que apresenta, nesta fase, maior proporção de colmo e material morto, que possui mais componentes estruturais, como a lignina, que as folhas. Ao longo do período de pastejo, ocorre incremento no conteúdo de parede celular das plantas, aumentando, conseqüentemente, o teor de FDN da forragem (Van Soest, 1982). O valor médio de FDN (41,6\%) está abaixo do encontrado por Grise et al. (2001), de 57,3\%, em mistura de aveia preta e ervilha forrageira. O NRC (1996) cita 61\% como teor médio de FDN em pastagem de azevém anual, diferença que pode ser atribuída à origem do material, que, neste experimento, foi proveniente da simulação de pastejo.

Segundo o NRC (1996), os teores de PB, NDT e FDN devem ser de 17,$4 ; 70,0$; e $42,8 \%$, respectivamente para que o farelo de trigo possa ser considerado de boa qualidade. $\mathrm{O}$ farelo de trigo utilizado neste experimento apresentou teores de 22,2; 65,5 e 42,0\% de PB, NDT e FDN, respectivamente, estando entre os valores recomendados.

A redução no teor de $\mathrm{PB}$ e o aumento da FDN da forragem aparentemente consumida pelos animais, com o avanço do período de pastejo, coincidem com o avanço nos estádios de desenvolvimento das plantas, em que ocorre aumento dos tecidos de sustentação constituídos por carboidratos estruturais e lignina (Blaser, 1990).

\section{Conclusões}

O crescimento da pastagem não é afetado, com taxa de acúmulo semelhante, quando os animais em pastagem com oferta de forragem média de 7,4 kg de matéria seca $/ 100 \mathrm{~kg}$ de peso vivo recebem suplemento.

O uso de suplemento e a variação no seu nível (de 0,3 a $1,5 \%$ do peso vivo dos animais), no decorrer do ciclo da pastagem de aveia e azevém, não interferem no teor de proteína bruta e na digestibilidade de nutrientes digestíveis totais e fibra em detergente neutro da forragem consumida pelos animais, os quais são influenciados pelo ciclo das forrageiras.

\section{Literatura Citada}

ASSOCIATION OF OFFICIAL ANALITICAL CHEMISTS AOAC. Official methods of analysis. 15.ed. Arlington: 1990. 1298 p.

BLASER, R.E. Manejo do complexo pastagem-animal para avaliação de plantas e desenvolvimento de sistemas de produção de forragens. In: PEIXOTO, A.M.; MOURA, J.C.; FARIA, V.P. (Eds.) Pastagens: fundamentos da exploração racional. 2.ed. Piracicaba: Fundação de Estudos Agrários "Luis de Queiroz", 1990. p.157-205.

BURNS, J.C.; LIPKE, H.; FISCHER, D.S. Grazing research: design, methodology and analysis. In: MARTEN, G.C. (Ed). The relationship of herbage mass carachteristics to animal responses in grazing experiments. Madison: 1989. p.7-19.

CANTO, M.W. Produção de cordeiros em pasto de azevém (Lolium multiflorum Lam.) mais trevo branco (Trifolium repens $L$.) submetida a níveis de resíduos de forragem. Santa Maria: Universidade Federal de Santa Maria, 1994. 181p. Dissertação (Mestrado em Zootecnia) - Universidade Federal de Santa Maria, 1994.

CANTO, M.W.; CECATO, U.; PETERNELLI, M. et al. Efeito da altura do capim-Tanzânia diferido nas características da pastagem no período do inverno. Revista Brasileira de Zootecnia, v.30, n.4, p.1186-1193, 2001.

CARVALHO, P.C. Relações entre a estrutura da pastagem e o comportamento ingestivo de ruminantes em pastejo. In: SIMPÓSIO SOBRE AVALIAÇÃO DE PASTAGENS COM ANIMAIS, 1997, Maringá. Anais... Maringá: 1997. v.1, p.25-52.

EMBRAPA. Centro Nacional de Pesquisa de Solos. Sistema brasileiro de classificação de solos. Brasília: EMBRAPA. Rio de Janeiro. 412 p. 1999.

EUCLIDES, V.P.B. Alternativas para intensificação da produção de carne bovina em pastagem. Campo Grande: Embrapa Gado de Corte, 2000. 65p.

EUCLIDES, V.P.B.; MACEDO, M.C.M.; OLIVEIRA, M. P. Avaliação de cultivares de Panicum maximun em pastejo. In: REUNIÃO ANUAL DA SOCIEDADE BRASILEIRA DE ZOOTECNIA, 36., 1999, Porto Alegre. Anais... Porto Alegre: Sociedade Brasileira de Zootecnia/Videolar, 1999. CD-ROM FOR-020.

EUCLIDES, V.P.B.; MACEDO, M.C.M.; OLIVEIRA, M. P. Avaliação de diferentes métodos de amostragem sob pastejo. Revista Brasileira de Zootecnia, v.21, n.4, p.691-702, 1992

FLOSS, E.L. Aveia. In: BAIER, A.C.; AUDE, M.I.S.; FLOSS, E.L. (Eds.). As lavouras de inverno-1. São Paulo: Globo, 1989. p.76-106.

FREITAS, F.K.; ROCHA, M.G.; RESTLE, J. et al. Suplementação energética na recria de fêmeas de corte em pastagem cultivada de inverno. Produção Animal. Revista Brasileira de Zootecnia, v.34, n.4, p.1256-1266, 2005.

FRIZZO, A.; ROCHA, M.G.; RESTLE, J. et al. Produção de forragem e retorno econômico da pastagem de aveia e azevém sob pastejo com bezerras de corte submetidas a níveis de suplementação energética. Revista Brasileira de Zootecnia, v.32, n.3, p.632-642, 2003.

GENRO, T.C.M.; ROCHA, M.G.; FREITAS, F.K. Dinâmica de uma pastagem de gramíneas de estação fria sob pastejo contínuo. In: REUNIÓN LATINOAMERICANA DE PRODUCCIÓN ANIMAL, 17., 2001, Havana. Memorias... Havana: SOFTCAL, 2001. p.2347-2349.

GIBB, M.J.; TREACHER, T.T. The effect of herbage allowance on herbage intake and performance of lambs grazing perennial ryegrass and red clover swards. Journal of Agricultural Science, v.86, p.355-365, 1976.

GOERING, H.K.; Van SOEST, P.J. Forage fiber analysis (apparates, reagents, procedures and some applications). USDA Agricultural Research Service, 1970. (Handbook, 379) GOMIDE, J.A.; GOMIDE, C.A.M. Utilização e manejo de pastagens. In: REUNIÃO ANUAL DA SOCIEDADE BRASILEIRA 
DE ZOOTECNIA. 38., 2001, Piracicaba. Anais... Piracicaba: Sociedade Brasileira de Zootecnia, 2001. p.808-825.

GONÇALVES, E.N.; SANTOS, D.T.; GENRO, T.C.M. et al. Dinâmica de uma pastagem de aveia (Avena strigosa SCHREB.) mais azevém (Lolium multiflorum LAM.) com ou sem o uso de suplementação para bezerras de corte. In: REUNIÃO ANUAL DA SOCIEDADE BRASILEIRA DE ZOOTECNIA, 39., 2002, Recife. Anais... Recife:Sociedade Brasileira de Zootecnia, 2002. CD-ROM.

GRISE, M.M.; CECATO, U.; MORAES, A. et al. Avaliação da composição química e da digestibilidade in vitro da mistura aveia IAPAR 61 (Avena strigosa Schreb.) + ervilha forrageira (Pisum arvense L.) em diferentes alturas sob pastejo. Revista Brasileira de Zootecnia, v.30, n.3, p.659-665, 2001.

HODGSON, J. Grazing management. Science into practice. Essex: Longman Group UK Ltda, 1990. p.203.

KLINGMAN, D.L.; MILES, S.R.; MOTT, G. The cage method for determining consumption and yield of pasture herbage. Journal of the American Society Agronomy, v.35, p.739-746, 1943 .

KLOSTER, A.; AMIGONE, M.A. Utilization de verdeos invernales bajo pastoreo en produccion de carne. Revista Argentina de Produccion Animal, v.19, n. 1, p.49-56, 1999.

LUPATINI, G.C.; RESTLE, J.; CERETTA, M. et al. Avaliação da mistura de aveia preta e azevém sob pastejo submetida a níveis de nitrogênio. Pesquisa Agropecuária Brasileira, Brasília, v.33, n.11, p.1939-1943, nov. 1998.

MORENO, J.A. Clima do Rio Grande do Sul. Porto Alegre: Secretaria da Agricultura, 1961.41p.

MOTT, G.O. Relationship of available forage and animal performance in tropical grazing systems. In: FORAGE GRASSLAND CONFERENCE, 1984, Houston. Proceedings... Lexington: American Forage and Grassland Council, 1984. p.373-377.

MOTT, G.O.; LUCAS, H.L. The design, conduct and interpretation of grazing trials on cultivated and improved pastures. In: INTERNATIONAL GRASSLAND CONGRESS, 6., 1952, Pensylvania. Proceedings... Pensylvania: SCP, 1952. p.1380-1395.

NATIONAL RESEARCH COUNCIL - NRC. Nutrient requirements of beef cattle. 7.ed. Washington, D.C., 1996.90p.

NATIONAL RESEARCH COUNCIL - NRC. Nutrient requirement of beef cattle. 6.ed. Washington, D.C.: National Academy Press, 1984. 90p.

PEDREIRA, C.G.S.; MELLO, A.C.L.; OTANI, L. O processo de produção de forragens em pastagens. In: REUNIÃO ANUAL DA SOCIEDADE BRASILEIRA DE ZOOTECNIA, 38., Piracicaba. Anais... Piracicaba: Sociedade Brasileira de Zootecnia, 2001. p.772-807.

PILAU, A.; ROCHA, M.G.; RESTLE, J. et al. Desenvolvimento de novilhas de corte recebendo ou não suplementação energética em pastagem com diferentes disponibilidades de forragem. Revista Brasileira de Zootecnia, v.34, n.5, p.14831492, 2005

PILAU, A.; ROCHA, M.G.; RESTLE, J. et al. Recria de novilhas de corte com níveis de suplementação energética em pastagem de aveia preta e azevém. Revista Brasileira de Zootecnia, no prelo, 2004.

PILLAR, V.D.P. Multivariate exploratory analysis and randomization testing with MULTIV. Coenoses, v.12, p.145-148, 1997.
PRACHE, S.; BECHET, G.; THERIEZ, M. Effects of concentrate supplementation and herbage allowance on the performance of grazing suckling lambs. Grass and Forage Science, v.45, p.423-429, 1990.

RESTLE, J.; LUPATINI, G.C.; ROSO, C. Eficiência e desempenho de categorias de bovinos de corte em pastagem cultivada. Revista Brasileira de Zootecnia, v.27, n.2, p.397-404, 1998.

ROCHA, M.G.; RESTLE, J.; FRIZZO, A. et al. Alternativas de utilização da pastagem hibernal para recria de bezerras de corte. Revista Brasileira de Zootecnia, v.32, n.2, p.383-392, 2003.

ROCHA, M.G.; PILAU, A.; SANTOS, D.C. et al. Desenvolvimento de novilhas de corte submetidas a diferentes sistemas alimentares. Revista Brasileira de Zootecnia, v.33, n.6, p.2123-2131, 2004 (supl.2).

ROSO, C.; RESTLE, J. Aveia preta, triticale e centeio em mistura com azevém. 2. Produtividade animal e retorno econômico. Revista Brasileira de Zootecnia, v.29, n.1, p.85-93, 2000.

ROSO, C.; RESTLE, J.; SOARES, A. S. et al. Aveia preta, triticale e centeio em mistura com azevém. 1. Dinâmica, produção e qualidade de forragem. Revista Brasileira de Zootecnia. v.29, n.1, p.75-84, 2000.

ROSO, C.; RESTlE, J.; SOARES, A.B. et al. Produção e qualidade de forragem da mistura de gramíneas anuais de estação fria. Revista Brasileira de Zootecnia, v.28, n.3, p.457-467, 1999.

ROSO, D.; PILAU, A.; ROCHA, M.G. et al. Taxa de acúmulo e oferta de forragem em aveia mais azevém sob pastejo de bezerras recebendo suplementação energética. In: REUNIÃO ANUAL DA SOCIEDADE BRASILEIRA DE ZOOTECNIA, 40., 2003, Santa Maria. Anais... Santa Maria: SBZ, 2003. CD-ROM.

STATISTICAL ANALYSES SYSTEM - SAS. SAS/STAT user's guide: statistics. 4.ed. Version 6. Cary: 1996. v.2, 943p.

SOARES, A.B.; RESTLE, J. Adubação nitrogenada em pastagem de triticale mais azevém sob pastejo com lotação contínua: recuperação de nitrogênio e eficiência na produção de forragem. Revista Brasileira de Zootecnia, v.31, n.1, p.45-51, 2002b.

SOARES, A.B.; RESTLE, J. Produção animal e qualidade de forragem de pastagem de triticale e azevém submetida a níveis de adubação nitrogenada. Revista Brasileira de Zootecnia. v.31, n.2, p.908-917, 2002 (suplemento).

TILLEY, J.M.A.; TERRY, R.A.A. Two stage technique for the "in vitro" digestion of forage crops. Journal of British Grassland Society, v.18, n.2, p.104-111, 1963.

Van SOEST, P.J. Nutritional ecology of the ruminant. 2.ed Ithaca: Cornell University Press, 1994. 476p.

Van SOEST, P.J. Nutritional ecology of ruminant. New York: Cornell University Press, 1982. 373p.

WILM, H.G.; COSTELLO, D.F.; KLIPPLE, G.E. Estimating forage yield by the double-sampling methods. Journal of American Society of Agronomy, v.36, p.194-203, 1944.

Recebido em: 31/05/04

Aceito em: 22/03/05 